\title{
Whatever Happened to the Nursing Process?
}

\author{
Peter Wells, Consultant in Adolescent Psychiatry to the Mersey and North West Regional Health Authorities, Young
} People's Unit, Victoria Road, Macclesfield

The introduction of a systematic approach to their work by nursing colleagues in the last decade provoked a great deal of comment and literature ${ }^{1.2}$ some of it amusing if perhaps slightly dismissive. ${ }^{3}$ Not a great deal is known about how widespread is the practice, or how well it is working in places where it has been adopted. Indeed the DHSS has set up a working party within the Nurse Education Research Unit of King's College to obtain enough basic information with a view to developing a research project into the effectiveness of the nursing process.

In view of this it was felt that it might be of interest to describe an experience of using the nursing process in the field of adolescent psychiatry.

The function of the Young People's Unit in Macclesfield has been described more fully elsewhere. ${ }^{4}$ Briefly, a service spanning two regions is based on a twenty-bedded adolescent unit in Macclesfield. About 50 out of 200 referrals a year are admitted to the five day unit, the remainder being dealt with as out-patients. About $94 \%$ of the admissions present with severe emotional and-or conduct disorders.

Admission to the unit is based on the successful negotiation of a provisional treatment plan with the young ster, his (or her) family or its substitute, and the referring agency. The plan expresses in simple language the number of problem behaviours which the youngster and his parents (if involved) agree to work to change. The youngster is then given a three week assessment period following which he is offered a firm contract. This implies a commitment to stay (usually for two or three months) and to work with us to change. Progress on the goals identified in the contract is reviewed monthly with the youngster, his parents and the referring agency. Over two years ago the Nursing Officer and the Consultant realised that the nursing process, concerned as it is with assessment, planning, implementation and evaluation seemed to dovetail extremely well with our contract system. It was ultimately adopted for the multi-disciplinary team.

Assessment As mentioned earlier, the unit offers every young person a three week assessment before offering a treatment contract. Assessment, however, used to consist of canvassing random impressions from the team about each youngster's motivation to work on his planned goals, and it lacked precision. Accordingly, the Principal Psychologist and the Consultant designed an assessment instrument, called a profile, which attempted to garner the maximum number of observations on the youngster's behaviour in the unit community, in counselling, group therapy, drama, art, social skills, family therapy, parent's support group and school, from a variety of key therapists.
Each therapist completes an assessment sheet consisting of pairs of contrasting statements separated by five columns. A tick is placed in one of the five columns to indicate how close the youngster's behaviour is to one or another contrasting statement.

At the youngster's case review at the end of the three week assessment period, reports are made by the relevant staff members on the youngster's progress and performance in the various treatment settings. Progress in the family is also reported by staff involved in family therapy and in the two weekly parent's support group meetings. These clinical impressions are supplemented by information from the youngster's profiles with its emphasis on motivation to change and capacity to learn from experience. This detailed information provides a basis for the team to negotiate a firm treatment contract with the family, or in a few cases to extend this assessment period for a further three weeks.

At the contract meeting, the youngster and his family are given a full summary of the assessment findings before making the agreement. The contract then expresses in clear language what changes on which the youngster and family wish to work and may define the roles of other partners, such as the referring agency representative.

Planning and Implementation In order to plan or modify treatment, the team reviews each inpatient's progress every four weeks before a monthly meeting - called the contract review-takes place with the youngster, the family and the referring agency. We attempt to make all important decisions affecting the youngster at the contract review to which all partners to the agreement are invited.

The team case review immediately before each contract review provides a facilitative structure for the following functions:

(1) Much detailed information can be processed in a systematic way.

(2) The major presenting problems and any new ones emerging since the previous review can be identified.

(3) Problem solving tasks can be assigned to particular therapists.

(4) The progress or outcome of earlier therapeutic tasks can be checked and evaluated.

To carry out these functions the team have found it helpful to display a problem solving task sheet for each youngster reviewed (Fig. 1).

Evaluation To enable us to evaluate if the problems with which each youngster presents are treated effectively, each young person, his parents and referring agency complete an evaluation, called a performance indicator, before 


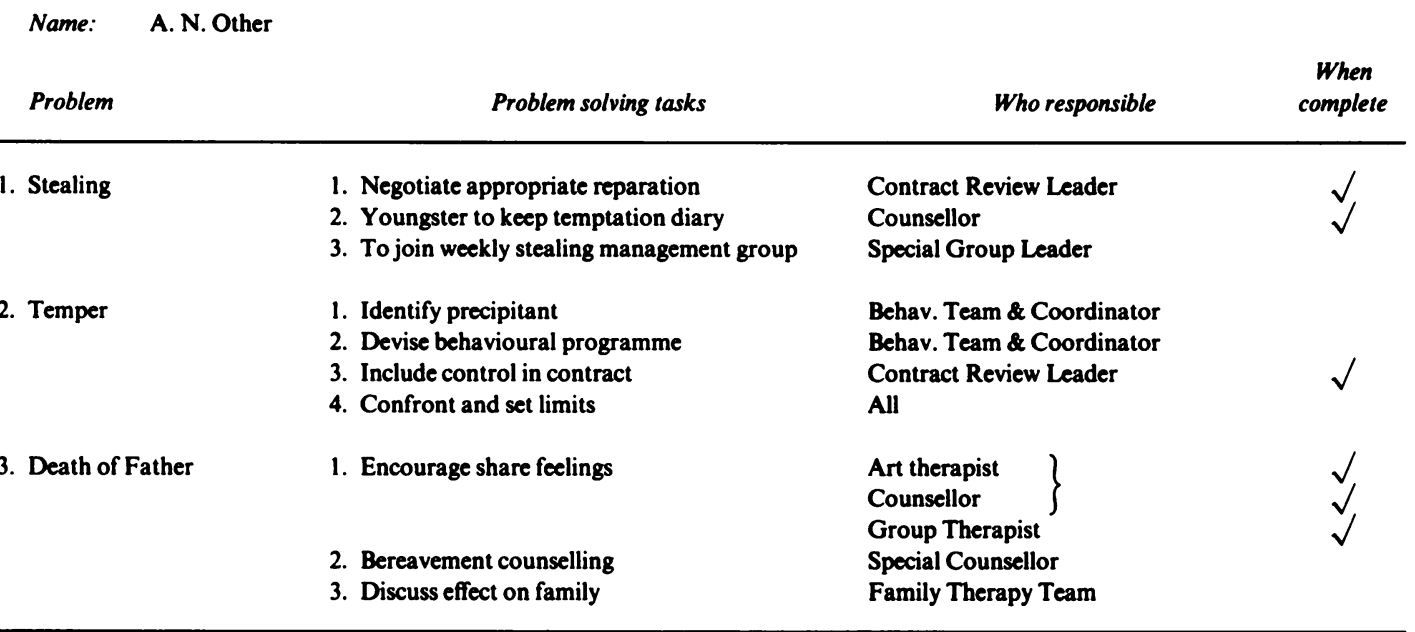

Fig. 1. Example of a youngster's task sheet displayed at the monthly team review.

admission, and one month, one year and two years after discharge. The performance indicator lists each problem behaviour, under which is a rating scale 0 to 8 $(0=$ completely satisfactory; $8=$ completely unsatisfactory). The sequential aggregate scores provide a measure of improvement or deterioration for two years after leaving the unit.

The results, which are encouraging, especially in the treatment of conduct disorders will be the subject of a further paper.

\section{Comment}

The authors of an earlier study of the results of treatment on the Young People's Unit ${ }^{4}$ gave their view that treatment might become more effective if it was designed to be more symptom-specific. As the authors commented, "the hopeful expectancy that the exposure of youngsters to artificially fostered good relationships, the development of insight into the determinants of their behaviour and the salutary experience of the frequent costly consequences of antisocial behaviour should suffice to mediate change in many exhibiting conduct and mixed disorders, has not been fulfilled". Use of the nursing process-now a multidisciplinary one-has proved a valuable discipline for all the team to focus on youngsters' specific problems and to find appropriate, and individually tailored ways of accomplishing changes in their behaviour.

The difficulties in achieving a clear decision making process in a multi-disciplinary setting, have been stressed by several authors. ${ }^{3.6 .7 .8}$ On the Young People's Unit, the multi-disciplinary process has succeeded in crystallising out areas of responsibility, and has facilitated greater clarity in decision making, with less of the endless debate which once troubled therapeutic communities and clouded issues. The most important of all perhaps, has been its cohesive effect on the team which now functions in a much more goaldirected way.

\section{REFERENCES}

${ }^{1}$ Kratz, C. R. (1981 edition) The Nursing Process. London: Baillière Tindall.

${ }^{2}$ Mores, I. (1982) The nursing process in psychiatry. Bulletin of the Royal College of Psychiatrists, 9, 165-166.

${ }^{3}$ CuRRIE, C. T. (1978) The nursing process: revolutionary philosophy or passing phase? British Medical Journal, 289, 1218-1219.

'Wells, P. G., Morris, A., Jones, R. M. \& Allen, D. J. (1978) An adolescent unit assessed: a consumer survey. British Journal of Psychiatry, 132, 300-308.

${ }^{5}$ BenNet, D., FoX, C., Jowetr, T. \& SkYNNER, R. (1976) Towards a family approach in a psychiatric day hospital. British Journal of Psychiatry, 129, 73-81.

${ }^{6}$ Royal College of Psychatrists (1984) The responsibilities of the consultant in psychiatry within the National Health Service. Bulletin of the Royal College of Psychiatrists, 8, 123-126.

${ }^{7}$ WARDLE, C. (1978) Responsibilities of consultants in child family and adolescent psychiatry. Bulletin of the Royal College of Psychiatrists, April, 66-68.

${ }^{8}$ BAKER, A. A. (1978) The consultant, one who consults (an oracle). Bulletin of the Royal College of Psychiatrists, June, 110-111. 